\title{
Bang-Bang Controller Based STATCOM Connected Wind Generating System for Mitigation of Source Current Harmonics
}

\author{
Hemalatha.G. ${ }^{1}$, Jeyapradha . R .B ${ }^{2}$ \\ ${ }^{\# 1}$ PG Scholar, Valliammai Engneering College, India 603203. \\ ${ }^{\# 2}$ Assistant Professor, Department of EEE, Valliammai Engineering College, India 603203
}

\begin{abstract}
This paper work is aimed at developing a STATCOM-based control scheme for mitigating source current harmonics in a grid-connected wind generating system. A bang-bang controller which is based on hysteresis current control scheme is developed for STATCOM and the performance of the control scheme is investigated through a test system modeled in MATLAB/SIMULINK platform. Simulation results are presented to demonstrate the impact of integration of wind generating system with the grid and the effectiveness of the STATCOM control scheme in minimizing the impact.FFT analysis carried out for the source current shows that the THD is considerably reduced and is clearly within limits imposed by standards with STATCOM connected at point of common coupling (PCC).
\end{abstract}

Keywords - Battery Energy Storage System (BESS), Power Quality (PQ), Point Of Common Coupling (PCC), Wind generating System (WGS), wind turbine generating system (WTGS).

\section{INTRODUCTION}

The need for providing reliable and secure power supply arises with an ever increasing demand for electricity. In recent years, the use of non-conventional sources for electricity generation has been gaining popularity and one such source is wind energy. The success of wind energy generating system lies in the capability of wind technology to be integrated into existing power system. However, the fluctuating nature of wind and the comparatively new types of its generators affect the power quality when the wind power is injected into the grid. In order to address the power quality issues that arise due to the integration of wind turbine with the grid, the grid operators have imposed stringent regulations requiring the wind turbines and wind farms to full fill power plant properties. This necessitates the use of highly sophisticates and flexible technology [3]. The performance of the wind turbine and thereby power quality are assessed through the guidelines specified by IEC-61400 standard.

In this paper work, a grid connected wind generating system is modeled in MATLAB/SIMLINK environment and its performance is studied. The introduction of harmonics in the source current waveform due to installation wind turbine with the grid is depicted. A FACTS devices (STATCOM) is connected at the point of common coupling with a Battery Energy Storage System (BESS) to make the source current free of harmonics[8]. A simple control scheme based on hysteresis current control is developed for the STATCOM with the following objectives:

- Unity power factor at the source side.

- Minimize the percentage THD in source current waveform.

The paper is organized as follows: Section II introduces the power quality standards, issues and its consequences. Section III describes the test system. Section IV describes the control scheme. Section V, VI, and VII discuss the test system waveform/results and conclusion.

\subsection{Harmonics}

\section{Power Quality Issues AND ITS CONSEQUenCES}

The harmonic results due to the switching operation of power electronic converters. The harmonic voltage and current should be limited to the acceptable level at the point of wind turbine connection to the network [10].

\subsection{Voltage Sag (Or Dip)}

A decrease of normal voltage level between 10 to $90 \%$ of the nominal rms voltage level at power frequency for duration of 0.5 cycle to one minute. It occurs due to connection of heavy loads and start-up of large motors. 


\subsection{Voltage spikes}

Very fast variation of the voltage values for durations from a several microseconds to few milliseconds. It occurs due to disconnection of heavy loads.

\subsection{Voltage Swell}

Momentary increase of voltage, at the power frequency, outside the normal tolerances, with duration of more than one cycle and typically less than a few seconds. It is caused due to badly regulated transformers (mainly during off-peak hours).

\subsection{Voltage fluctuation}

A series of voltage changes or a continuous variation of the R.M.S voltage . It is caused due to frequent start/stop of electric motors (for instance elevators), Oscillation in loads.

\subsection{Very Short Interruption}

Total interruption of electrical supply for duration from few milliseconds to one to two seconds . It is caused due to insulation failure, lightning and insulator flashover.

\subsection{Long Interruptions}

Total interruption of electrical supply for duration greater than 1 to 2 seconds. It occurs due to equipment failure in the power system network.

\subsection{Consequences of the issues}

The voltage variation, flicker, harmonics causes the mal-function of equipment namely microprocessor based control system, programmable logic controller. It may lead to tripping of contractors, tripping of protection devices, stoppage of sensitive equipments like personal computer, programmable logic control system and may stop the process and even can damage of sensitive equipments. Thus it degrades the power quality in the grid [3].

\section{TEST SYSTEM DESCRIPTION}

The test system in Fig.1 consists of Wind generating system connected to the grid with non linear load [10]. The STATCOM with battery energy storage is connected at the point of common coupling. The controller used with STATCOM is BANG-BANG controller that generates switching signals for STATCOM operation. The various parameters used with the test system for simulation are listed in Table 1.

\subsection{Wind Energy Generating System:}

The wind energy generating system considered here is based on constant speed topology with pitch control turbine. The wind farm model uses a Induction generator owing to its simplicity. Also, it does not require a separate field circuit, can accept constant and variable loads and has inherent short circuit protection [7].

\subsection{STATCOM:}

The grid connected wind generating system model consists of a shunt connected STATCOM with Battery Energy Storage connected at the interface of induction generator and non-linear load [1]. The grid voltages are sensed by the controller and are synchronized to generate the current command for the inverter. The STATCOM inject current into the grid in such a way that the source current is harmonic free and hence power quality is improved.

\subsection{System Operation:}

The shunt connected STATCOM with battery energy storage is connected with the interface of the induction generator and non-linear load at the PCC in the grid system. The STATCOM compensator output is varied according to the controlled phase voltage.The grid connected Wind Generating System model consists of a shunt connected STATCOM with Battery Energy Storage connected at the interface of induction generator and non-linear load [1].The grid voltages are sensed by the controller and are synchronized to generate the current command for the inverter.The STATCOM injects current for the inverter.TheSTATCOM injects current into the grid in such a way that the source current is harmonic free and hence power quality is improved. 


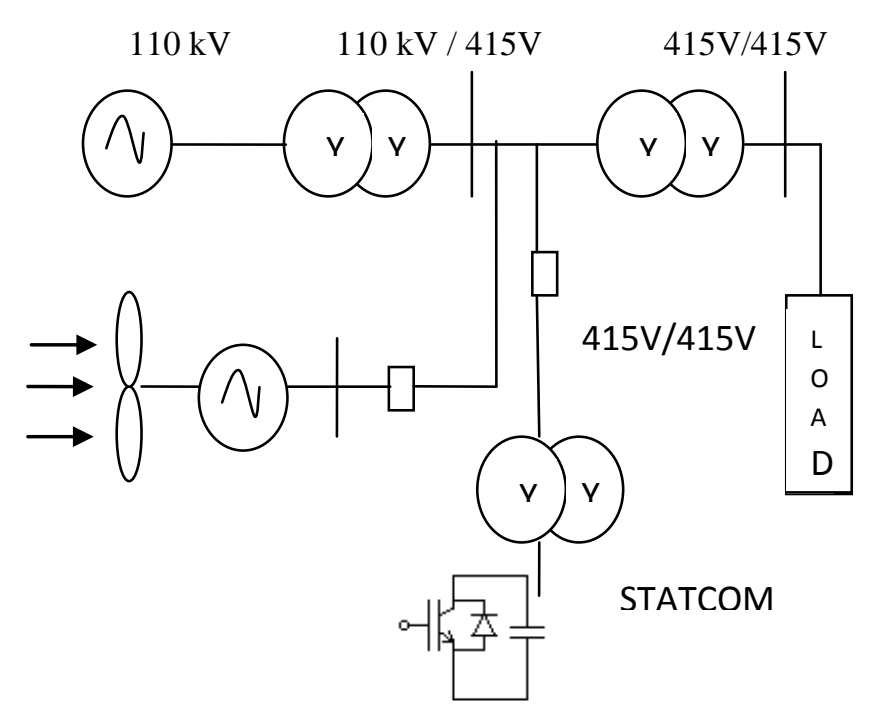

Fig.1 Test system of Wind farm connected to grid

\section{Control Scheme}

The control scheme approach is based on injecting the currents into the grid using "bang-bang controller." The controller uses a hysteresis current controlled technique. Using such technique, the controller keeps the control system variable between boundaries of hysteresis area and gives correct switching signals for STATCOM operation. Fig 2 presents schematic of BANG-BANG controller used with STATCOM [1].

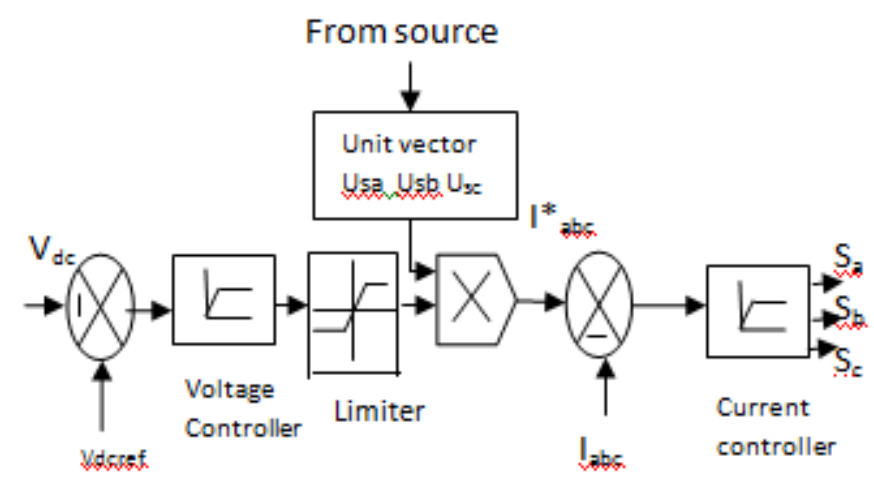

Fig.2 Schematic of BANG-BANG controller

In three-phase balance system, the RMS voltage amplitude is calculated at the sampling frequency from the source phase voltage $\mathrm{V}_{\mathrm{sa}}, \mathrm{V}_{\mathrm{sb}}, \mathrm{V}_{\mathrm{sc}}$ and is expresses, as sample template $V s m$, sampled peak voltage, as in (1).

$$
V_{m m}=\left\{2 / 3\left(V_{m s}^{2}+V_{g b}^{2}+V_{g m}^{2}\right)\right\}^{1 / T^{2}}
$$

The in-phase unit vector are obtained from AC source phase voltage and RMS value of unit vector $U_{s c}, U_{s b}, U_{s c}$ as show in (2)

$$
U_{s a}=\frac{V_{s a}}{V_{s m}}, U_{s b}=\frac{V_{s b}}{V_{s m}}, U_{s c}=\frac{V_{s C}}{V_{s m}}
$$

The in-phase generated reference currents are derived using in-phase generated reference currents are derived using in-phase unit voltage template as, in (3).

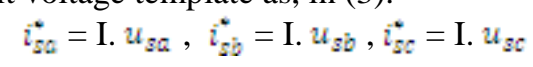

where I is proportional to magnitude of filtered source voltage for respective phase. This ensue source current is controlled to be sinusoidal. The unit vectors implement the important function in the grid connection for the synchronization for STATCOM. This method is simple, robust and favorable as compared with other methods [1]. 


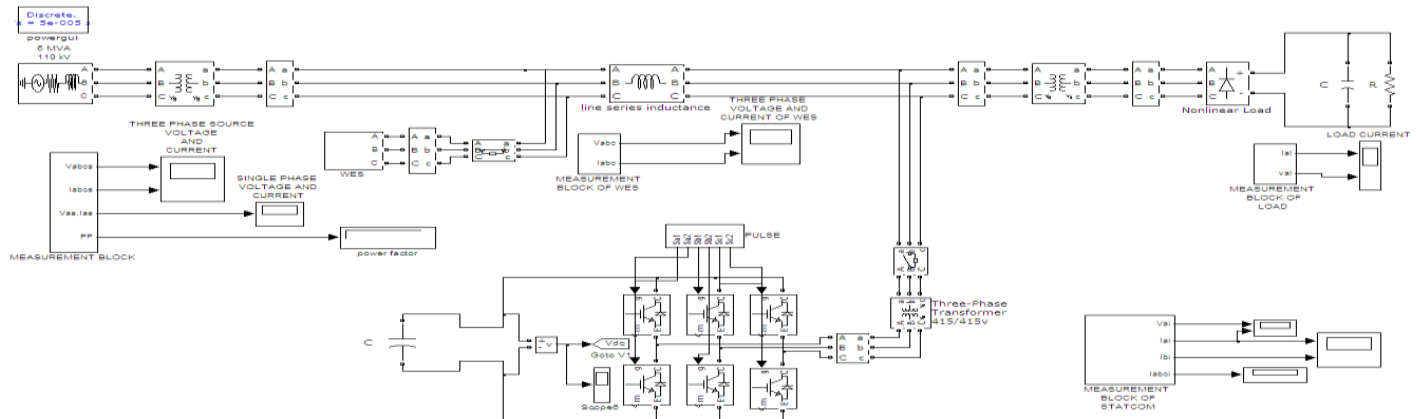

Fig.3 Simulation model of grid connected wind generating system with STATCOM

\section{Simulink Modeling Of Statcom-Based Control Scheme For Grid Connected Wind Generating System}

Simulation model of grid connected wind generating system with STATCOM is shown in the Fig.3 and the parameters used for the simulation is listed in Table 1.

Table 1: System parameters

\begin{tabular}{|c|c|c|}
\hline SL.NO & $\begin{array}{l}\text { PARAMETERS } \\
\text { GRID } \\
\text { VOLTAGE }\end{array}$ & $\begin{array}{r}\text { RATING } \\
3 \text { phase, } 415 \mathrm{~V}, 50 \mathrm{~Hz}\end{array}$ \\
\hline 2 & $\begin{array}{l}\text { ASYNCHRONO } \\
\text { US } \\
\text { MOTOR/GENE } \\
\text { RATOR }\end{array}$ & $\begin{array}{l}275 \mathrm{Kva}, 480 \mathrm{~V}, 50 \mathrm{~Hz} \\
\mathrm{p}=4, \mathrm{Speed}=1440 \mathrm{rpm}, \\
\mathrm{Rs}=0.010 \mathrm{mhs}\end{array}$ \\
\hline 3 & $\begin{array}{l}\text { PARAMETERS } \\
\text { INVERTER }\end{array}$ & $\begin{array}{l}\mathrm{DC} \text { link volta ge }=1200 \mathrm{~V} \text {, } \\
\text { frequency }=2 \mathrm{KHz}\end{array}$ \\
\hline 4 & IGBT RATING & $\begin{array}{l}\text { Collector voltage }=1200 \mathrm{~V} \text {, } \\
\text { Forward current }=50 \mathrm{~A} \text {, } \\
\text { Gate volta ge }=20 \mathrm{~V} \text {. }\end{array}$ \\
\hline 5 & $\begin{array}{l}\text { LOAD } \\
\text { PARAMETERS }\end{array}$ & Non-Linear Load $25 \mathrm{Kw}$ \\
\hline
\end{tabular}

\section{Simulation Results and Discussion}

CASE 1: Test system without Wind farm and STATCOM

In this case, the source is directly connected to non linear load without wind farm and STATCOM. Fig 4 shows the source voltage and current waveforms for case1. It is observed from Fig 4 that the source current of the grid is distorted due to the effects of nonlinear load.

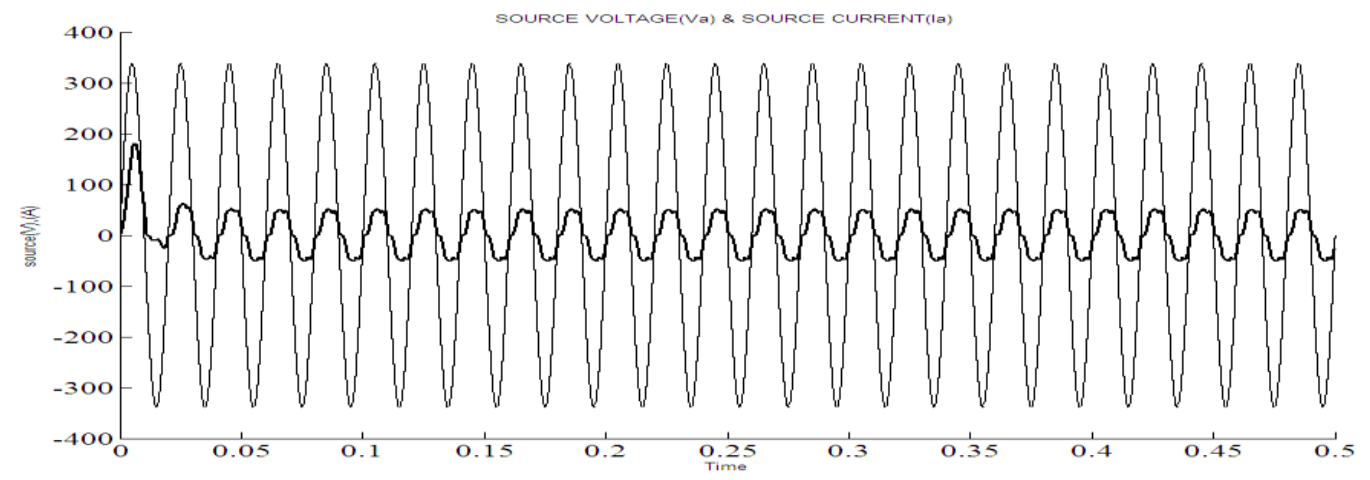

Fig.4 Source voltage and current waveforms of test system without wind farm and STATCOM CASE 2: Wind farm connected to grid without STATCOM 
Here, the wind farm is connected to the grid. The current and voltage waveforms of source are depicted in Fig 5. From the Fig 5, it is observed that the source current waveform is highly distorted due to the integration of wind generating system with the grid. Fig 7 presents the FFT analysis for grid connected wind energy system without STATCOM. It shows that the total harmonic distortion for the source current waveform without STATCOM is $27.88 \%$.

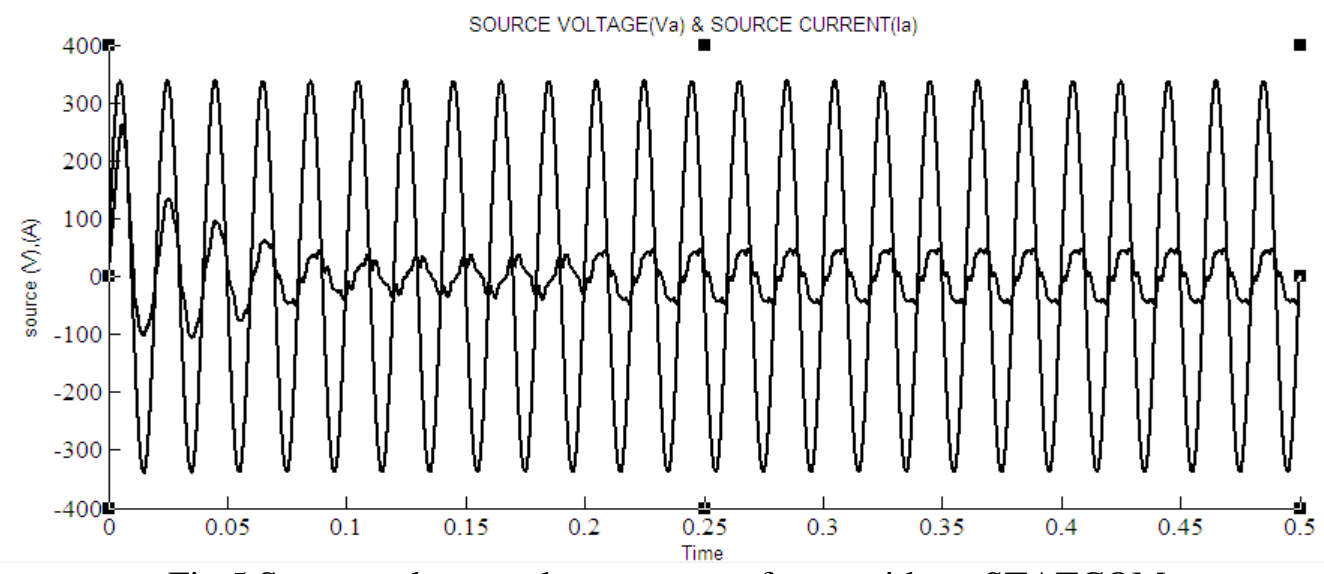

Fig.5 Source voltage and current waveforms without STATCOM

CASE 3: Wind farm connected to grid with STATCOM

Here, the STATCOM is connected to the grid connected wind generating system at $0.2 \mathrm{~s}$. The source voltage and current waveforms for this case are presented in Fig 6. It is observed from Fig 6 that when the STATCOM controller is switched ON at $0.2 \mathrm{~s}$, without change in any other load condition parameters, it starts to mitigate the harmonics present otherwise. Fig 8 presents the FFT analysis for grid connected wind energy system with STATCOM. It shows that the total harmonic distortion for the source current waveform with STATCOM is $4.9 \%$ which is within the limits imposed by the standards. Thus the performance of the controller designed for STATCOM is satisfactory as it helps in successfully minimizing the source current harmonics introduced by the wind generating systems.

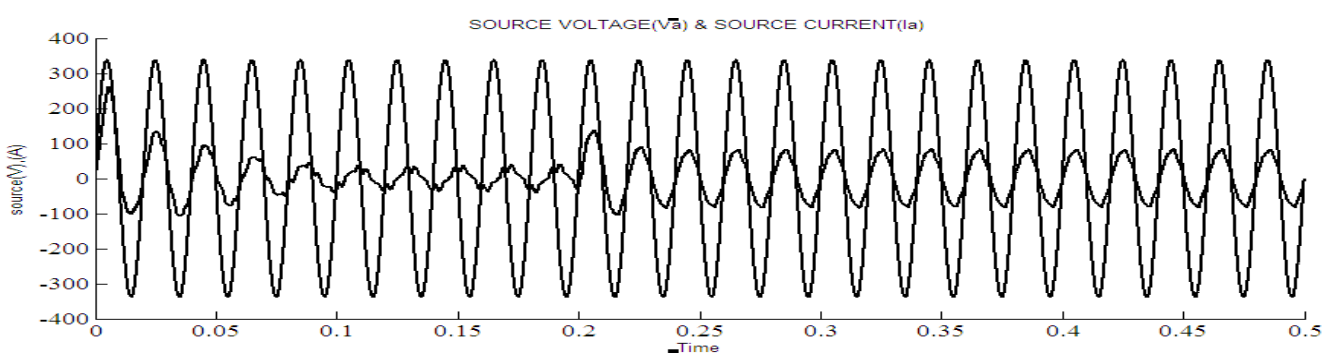

Fig.6 Source voltage and current waveforms with STATCOM

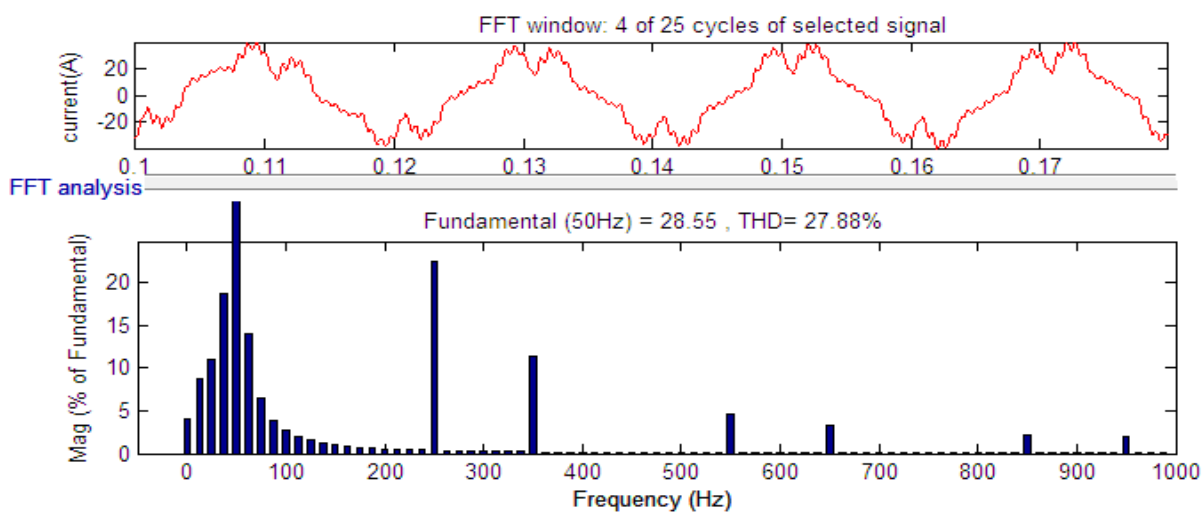

Fig.7FFT analysis of source current for the test system without STATCOM 


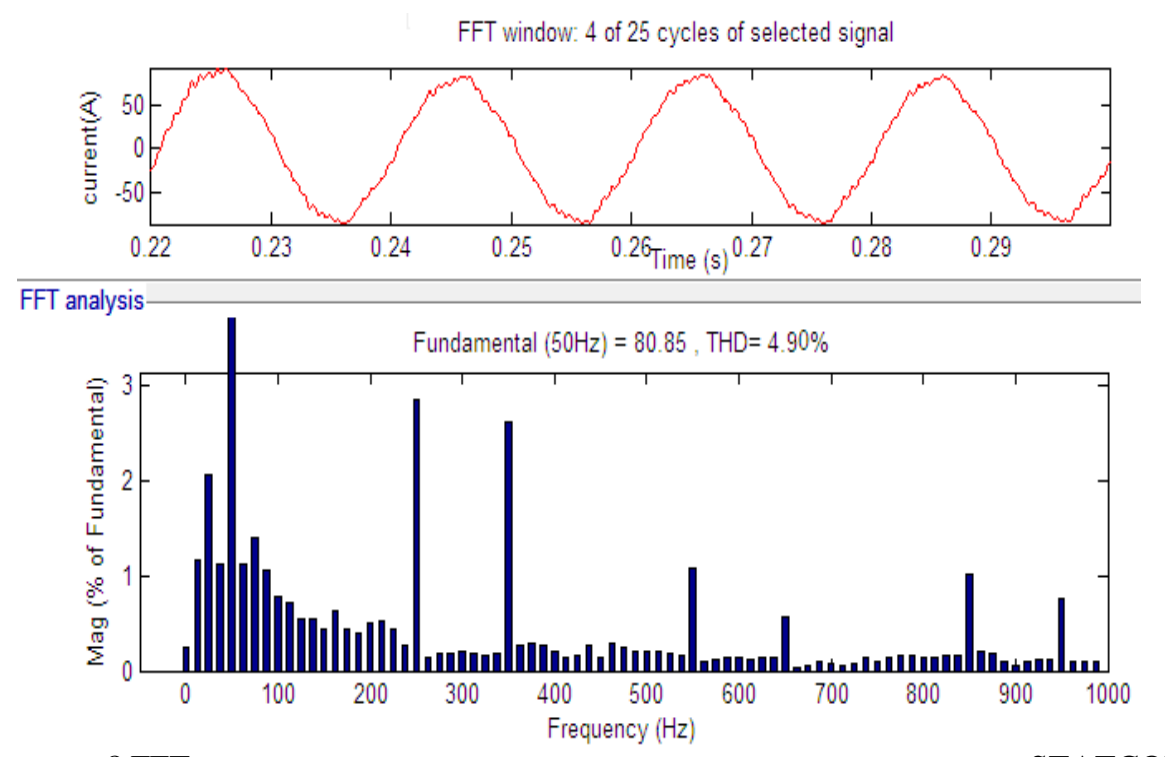

FIG.8 FFT ANALYSIS OF SOURCE CURRENT FOR THE TEST SYSTEM WITH STATCOM

\section{CONCLUSION}

In this paper, the effect of integrating the wind generator with the electric grid was addressed. A test system for grid connected wind generating system with non-linear load and STATCOM connected at point of common coupling (PCC) was developed in MATLAB/SIMULINK environment. A controller based on hysteresis current control scheme was devised for the STATCOM and its effectiveness in minimizing the harmonics in the source current waveform from was studied by investigating the waveform before and after STATCOM operation. It was observed from the simulation results that the THD in the source current waveform has been greatly reduced from $27.88 \%$ to $4.90 \%$ with the use of STATCOM.

\section{Journal Papers:}

\section{REFERENCES}

[1] Sharad W. Mohad, and Mohan V. Aware," A STATCOM-control scheme for Grid Connected Wind Energy System for Power Quality Improvement," IEEE SYSTEMS JOURNAL, VOL 4 NO 3,SEP 2010.

[2] H. Hassan .El- Tamaly*, Mohamed A. A. Wahab and Ali H. Kasem, "Simulation of Directly Grid-Connected Wind Turbines for Voltage Fluctuation Evaluation," International Journal of Applied Engineering Research ISSN 0973-4562 Vol.2, No.1, pp. 15$30,2007$.

[3] H.M. Abdel_Mageed Sayed, S.M. Sharaf, S.E. Elmasry, M.E. Elharony, "Simulation of a Transient Fault Controller for a Grid Connected Wind Farm with Different Types of Generators", International Journal of Applied Engineering Research ISSN 0973-4562 Vol.2, No.1, pp. 15-30,2007.

[4] Sharad W. Mohad, and Mohan V. Aware," A STATCOM-control scheme for Grid Connected Wind Energy System for Power Quality Improvement," IEEE SYSTEMS JOURNAL, VOL 4 NO 3,SEP 2010.

[5] R.Ganesh.Harimanikyam1, R. Lakshmi Kumari, "Power Quality Improvement of Grid Connected Wind Energy System by STATCOM for Balanced and Unbalanced Linear and Nonlinear Loads," International Journal of Engineering Research and Development, Vol 3, PP. 09-17.Aug 2012.

[6] .R.Ganesh.Harimanikyam1, R. Lakshmi Kumari, "Power Quality Improvement of Grid Connected Wind Energy System by STATCOM for Balanced and Unbalanced Linear and Nonlinear Loads," International Journal of Engineering Research and Development,Vol 3, PP. 09-17.Aug 2012

[7] Sreekanth, N. Pavan Kumar Reddy, "PI \& Fuzzy logic based controllers STATCOM for grid connected wind generator", International journal of Engineering Research and Application (IJERA).Vol.2,Issue 5,Sep-oct-2012.

\section{Conference Paper:}

[8] R. S. Bhatia, S. P. Jain, D. K. Jain, and B. Singh, "Battery energy storage system for power conditioning of renewable energy sources," in the Proceedings of International Conference on Power Electronic Drives System, vol. 1, pp. 501-506 Jan 2006N. 